\title{
Endüstri 4.0 Devriminde Robotik Kaynaklar Yönetimi Bağlamında İnsan Kaynakları Yönetiminde Yeni Açılımların Kaçınılmazlığı
}

A. Aslan ŞENDOĞDU ${ }^{1}$

\begin{tabular}{lcc}
\hline \multicolumn{1}{c}{ Geliş Tarihi/ Received } & Kabul Tarihi/ Accepted & Yayın Tarihi/ Published \\
10/10/2019 & $27 / 12 / 2019$ & $25 / 01 / 2020$ \\
\hline Citation/Atıf: Şendoğdu, A., A., & (2020), Endüstri 4.0 Devriminde Robotik Kaynaklar Yönetimi \\
Bağlamında İnsan Kaynakları Yönetiminde Yeni Açılımların Kaçınılmazlığı, Atatürk Üniversitesi \\
Íktisadi ve İdari Bilimler Dergisi, 34(1): 168-184, DOI: 10.16951/atauniiibd.631617 \\
\hline
\end{tabular}

Öz: Endüstri 4.0 devrimi ile birlikte robotik uygulamaların, hayatımızın her alanına el attığı/el atmaya başladığ 1 bir süreci yaşamaktayız. Endüstri 4.0 dijital dönüşümlerle, robotik teknolojilerin büyük ölçüde insan kaynağının yerini alacağı, akıllı fabrikalar ve nesnelerin interneti ile bütünleşik bir yapıyı göstermektedir. Robotik uygulamaların yaygınlaşması, insan kaynağının yerinin robotik kaynaklara evrilmesi, İnsan Kaynakları Yönetimini yeni açılımlara doğru yönlendirmektedir.

Çalışmanın amacı, Endüstri 4.0 Devrimi ve dünyadaki gelişmeler 1şığında, İnsan Kaynaklar Yönetiminde yeni açılımlar için farkındalık yaratmaya katkı sağlamaktır. Çalışmada, robotik kaynakların hızla hayatımızın bir parçası haline geldiği günümüzde, yeni bir kavrama "Robotik Kaynaklar Yönetimi" (RKY) kavramına gereksinim duyulduğu sonucuna ulaşılmıştır. "Robotik Kaynaklar Yönetimi”nin İnsan Kaynakları Yönetimi'nin mütemmim cüzü (ayrılmaz parçası, tamamlayıcıs1) olarak tanınması gerekmektedir. Yakın gelecekte, İnsan Kaynakları Yönetiminin, optimum faydayı sağlayacak şekilde, "Robotik Kaynaklar Yönetimi" ile işbirliği içine girmesi kaçınılmaz olacaktır.

Anahtar Kelimeler: Endüstri 4.0 Devrimi, Yapay Zeka, Robot, Robotik Kaynaklar, Robotik Kaynaklar Yönetimi, İnsan Kaynakları Yönetimi.

\section{The Inevitability Of New Evolutions In Human Resources Management As Part Of Robotic Resources Management During The Industry 4.0 Revolution}

Abstract: Along with the Industry 4.0 revolution, we are experiencing a process in which robotic applications taking their hands on every aspect of our lives. Industry 4.0 illustrates a structure that is integrated the Internet of intelligent factories and objects with the digital transformations, where robotic technologies will largely replace human resources. Thanks to the spreading of robotic applications and the evolution of human resources to robotic resources, Human Resources Management science unfolds new robotic chapters.

The aim of this study is to contribute to raise awareness about new insights in Human Resources Management in the light of Industry 4.0 Revolution and developments in the world. At this study, it is concluded that there is a strong need for a new concept which is named as "Robotic Resources Management" (RRM), where robotic resources have become an unavoidable part of our lives. "Robotic Resources Management" should be recognized as integral and essential part of the Human Resources Management. In the near future, it will be inevitable for Human Resources Management to cooperate with "Robotic Resources Management", in order to provide optimum benefits for the industry.

Keywords: Industry 4.0 Revolution, Artificial Intelligence, Robot, Robot Resources, Robotic Resources Management, Human Resources Management.

${ }^{1}$ Doç. Dr. Necmettin Erbakan Üniversitesi, Uygulamalı Bilimler Fakültesi, Bankacılık Bölümü, https://orcid.org/0000-0002-9860-320X 
Endüstri 4.0 Devriminde Robotik Kaynaklar Yönetimi Bağlamında İnsan Kaynakları Yönetiminde Yeni Açılımların Kaçınılmazlı̆̆

\section{EXTENDED SUMMARY}

There have been many important milestones in the history of humanity. Processes starting with the industrial revolution, the speed of the developments has become much more faster than the previous periods. This speed has also increased with the globalization. The last link in this development process, which is Industry 4.0 revolution, is the focus of the whole world. In a world where change destroys those who resist it, making the right choice at the right time become much more vital than ever. To address this situation, robotic applications are developing rapidly in todays world.

Along with the Industry 4.0 revolution, we are experiencing a process in which robotic applications taking their hands on every aspect of our lives. Industry 4.0 illustrates a structure that is integrated the Internet of intelligent factories and objects with the digital transformations, where robotic technologies will largely replace human resources. Thanks to the spreading of robotic applications and the evolution of human resources to robotic resources, Human Resources Management science unfolds new robotic chapters.

A company which is investing in venture capital in Hong Kong has taken the first pioneering step in that field, by implementing an artificial intelligence member to the board of directors (https://www.hkdestek.com/terminoloji/ yonetim-kurunbir-bir-robot). It also gives an idea about the road map of the boards in the future. It will be inevitable that Human Resources Management will cooperate with so called "Robotic Resources Management" in order to provide optimum benefit in delegation of authority. One of the key areas that HRM will focus on in the future will be to find out to what extent robotic resources will provide the optimum efficiency.

Google-produced Alpha Zero's artificial intelligence learned how to play chess on its own in just four hours and defeated after the legendary computer chess program Stockfish with outstanding results (http://www.satrancokulu.com/yazilar/ makaleler/caissa-yasiyor-mu-3-alpha-zero-mucizesi/). Is it possible for a person to do that? Can artificial intelligence design another artificial intelligence? How effective artificial intelligence can be in decision-making situations as it were in Hong Kong? Can artificial intelligence monitor human performance? Are we going to try to get along with artificial intelligence? Will artificial intelligence decide whether we should be hired or fired? Can artificial intelligence take precedence over human decision-making and become the final decision-maker? The answers to these questions are vital to help us understand the future world. A period which contains the paradox of opportunity and threat is reaching rapidly than ever in human history. In the near future, robotic resources will also share strategic partner positions just like in human resources. In the light of technological developments, it can be said that a superior formation can be build with the cooperation of emotional intelligence of human resources and artificial intelligence of robotic resources. This could play a key role in decision-making processes and operational works of organizations.

The aim of this study is to contribute to raise awareness about new insights in Human Resources Management in the light of Industry 4.0 Revolution and 
developments in the world. At this study, it is concluded that there is a strong need for a new concept which is named as "Robotic Resources Management" (RRM), where robotic resources have become an unavoidable part of our lives. "Robotic Resources Management" should be recognized as integral and essential part of the Human Resources Management. In the near future, it will be inevitable for Human Resources Management to cooperate with "Robotic Resources Management", in order to provide optimum benefits for the industry.

\section{Giriş}

Değişimin, değişime direnenleri yok ettiği bir dünyada, doğru seçim, değişim için yönü doğru olarak belirlemek olacaktır. Günümüz dünyasında, robotik uygulamalar hızla gelişmektedir. Tokyo Üniversitesi'nden bilim insanlarının, canlı kas dokularını robotik bir parmak üzerine eklemlemeyi başarması (https://siberbulten.com/yapayzeka/japonlar-robota-canli-kas-ekledi/) robotların daha gerçekçi şekilde, insan gibi hareket etmesinin yolunu açmıştır. Robotik kaynaklardan yararlanmanın yakın gelecekte hayatımızın büyük bölümünde etkin rol oynayacağı gerçeğinden hareketle, yeni bir kavram geliştirmeye, "Robotik Kaynaklar Yönetimi" kavramına ihtiyaç duyulmaktadır.

İngiltere'de futbol takımı Finchley FC, ekibini yönetecek teknik direktörü bir yapay zekadan seçmesi (https://www.webtekno.com/ingiltere-de-bir-futbol-takimiekibin-basina-yapay-zekayi-getirdi-h61753.html), yakın gelecekte "Robotik Kaynaklar Yönetimi" ve İnsan Kaynakları Yönetimi işbirliğine işaret özelliği taşımaktadır.

Örgütlerde yakın gelecekte, robotik kaynaklar da insan kaynağının stratejik ortağı şeklinde konum paylaşımı yapacaktır. Gelişmeler 1şı̆̆ııda, insan kaynağına özgü duygusal zeka, robotik kaynağa özgü yapay zekanın harmanlandığı duygusal zeka \& yapay zeka gibi bir üst oluşumun örgütlerin karar verme süreçlerinde kilit rol oynayacağı söylenebilir.

\section{Endüstri 4.0'ın Kavramsal Çerçevesi}

Endüstri 4.0 kavramsal olarak ilk kez 2011'de Hannover Fuarı'nda gündeme gelmiş, Alman Hükümetince de konvansiyonel üretim metotlarından bilgisayar \& internet destekli otomasyonel üretim yöntemine geçişi sağlamak maksadıyla ortaya konulmuştur (Sung, 2017: 1). Aynı sene, Almanya'da yönetimdeki iktidarın stratejik bir hedefi olarak, Yüksek Teknoloji Stratejisinin 2020 Eylem Planı'na eklenmiştir. $\mathrm{Bu}$ sayede, Endüstri 4.0 terimi, geleceğin rekabet strateji kapsamında değerlendirilmiştir (Mrugalska \& Wyrwicka, 2017: 468; Aytaç, 2018: 547-548).

Endüstri 4.0 kavramı kuramsal boyutta ise ilk önce Kagerman ve arkadaşlarınca 2011 senesinde yayınlanmış olan "Endüstri 4.0: Nesnelerin İnterneti ile 4. Endüstri Devrimine Giderken" başlığını içeren makale ile gündem oluşturmuştur (Kagerman, vd., 2011). Adı geçen makalede dünya için yeni bir devreye girildiği ve bunun Endüstri 4.0 olarak adlandırılması gerektiği ifade edilmekte ve bu sürece ilişkin bileşenler hakkında malumat verilmektedir (Soylu, 2018: 45). 
Endüstri 4.0 Devriminde Robotik Kaynaklar Yönetimi Bağlamında İnsan Kaynakları Yönetiminde Yeni Açılımların Kaçınılmazlı̆̆ı

Endüstri 4.0 öz olarak, akıllı sistemler \& internet tabanlı çözümlerle ifade edilen, sanayileşme devrimlerinin dördüncü adımı olarak adlandırılmaktadır. Birinci Endüstri Devrimi etkin olarak su ve buhar kuvvetinden faydalanan fiziksel sistemlerin sahneye konulması ile yaşanmıştır. İkinci olarak yaşanan Endüstriyel devrimin fark yaratan özelliği, elektriğin, işbölümü ve kitle üretiminin ekonomide etkin konuma gelmiş olmasıdır. Üçüncü Endüstri Devrimi, üretim yöntemlerini otomatikleştirmek üzere elektronik, bilişim ve otomasyon teknolojilerinden yarar sağlanarak, farklılı̆̆ın ortaya konulmasından kaynaklanmıştır (Banger, 2017: 24). Son olarak, Endüstri 4.0 ise yüksek seviyede kişiselleşmiş ve çapraz bağlantılandırılmış üretim prosesleriyle (süreçleriyle) ifade edilmektedir (Schuster vd., 2015: 14).

Endüstri 4.0, ileri teknoloji uygulamaları stratejisi kapsamında, akıllı robotlarca üretimin devralınarak daha üstün kaliteli, daha esnek, daha ucuz ve hızlı üretim yapılabilmesi için, siber-fiziki sistemlerle, nesnelerin internetiyle, bilgi iletişim teknolojileri tabanlı tasarlanmış bir yakın gelecek vizyonudur (Yılmaz \& Erkollar, 2018: 2). Endüstri 4.0 devrimi getirdiği yeni dijital dönüşüm ile, Nesnelerin İnterneti ve akı1lı (karanlık) fabrikalarda öğrenen makineler ile temin edilen otonom işleyiş, örgütlere gerçek zamanlı data akışı ile proaktif yaklaşım ortamı sağlamaktadır (Tekin \& Uslu, 2018: 116).

Fiziki ve sanal dünyanın birlikteliğini sağlayan Endüstri 4.0 uygulamaları, ürün yaşam döngüsü kapsamında değer zincirinde alışılmışın dışında bir organizasyon seviyesine işaret etmektedir (Alçın, 2016: 22). Bu yüzden, Endüstri 4.0'ın getirdiği yeni teknolojiler, değer zinciri organizasyonları ile kolektif bir bütünü kapsamaktadır. Endüstri 4.0 devrimiyle modüler yapılı karanlık fabrikaları, fiziksel işlem süreçleri, siber-fiziksel sistemlerle takip etme, fiziksel alemin sanal bir biçimini oluşturarak merkezi olmayan kararların verilmesi düşünülmektedir (Lee, Bagheri \& Kao, 2015; Davutoğlu vd., 2017: 548).

\subsection{Endüstri 4.0'ın Getirdiği Başlıca Yenilikler}

Endüstri 4.0'in getirdiği başlıca yenilikler şöyle sıralanabilir:

- $\quad 3$ D Yazıcı teknolojisinin getirdiği yeniliklerle, birçok hammadde ve/veya üretim kombinasyonları sayesinde çok farklı sahalarda üretim gerçekleştirilebilmektedir. $\mathrm{Bu}$ sahalardan sarraflıktan genetiğe, bilişim teknolojilerinden akıllı şehir planlamasına, sağlıktan gıdaya, hemen her tür sanayi üretiminde uygulama alanı bulan 3D yazıcılarda modellemeye ilişkin olarak baskı süresinde de farklılık göstermektedir. 3D yazıcılar sayesinde; Biyo-organik maddenin damardan, organlara ve dokulara varıncaya kadar her türden üretim yapilabilmektedir (EBSO, 2015: 11).

- Nesnelerin Ínterneti (NI) sayesinde, nesne ve organizmaların tekil tanımlayıcılar üstünden, insan ile insan ve insan ile bilgisayar etkileşimine ihtiyaç olmadan yerel bir ağa veya internete bağlanarak veri aktarımı gerçekleştirilebilmektedir. NI bünyesindeki unsurlar kapsamında, vücudunda kalp implantı taşıyan bir insan, izlenme yongası bulunan bir hayvan, tekerleklerinde 


\section{A. Aslan $S B E N D O \breve{G} D$}

bulunan hava oranını izleyen bir taşıt ya da bir IP adresi atanarak network üzerinden veri aktarımı yapabilen doğal veyahut insanın ürettiği nesneler vasıtasıyla bilgi akışı mümkün olabilmektedir (Köroğlu, 2015: 1; Bulut \& Akçacı, 2017: 55-56).

- Akıllı Fabrikalar, sanayinin yeni ögeleri büyük veri, nesnelerin interneti ve robot teknolojileri gibi yeni sistemler ile ortaya çıkmıştır. Nesnelerin internetinin, sanayide, günlük yaşama benzer şekilde, robotik makinelerin internet ağları vasıtasıyla üretim süreçlerinin tamamında yer alabileceği görülmektedir. Bu yeni gelişme, iş alemini, akıllı üretim proseslerinde yerini alan akıllı fabrikalar ve bu akıllı fabrikalardan çıkan akıllı ürünlerle tanıştırmıştır (EBSO, 2015: 16).

- Büyük Veri, "sosyal medya tarafından yapılan paylaşımlar, bloglar, sistem logları, ağ günlükleri, fotoğraflar, videolar gibi farklı kaynaklardan sağlanan, işlenebilen ve bu işlenme sonucu anlamlandırılabilen veri şekline dönüştürülme biçimi” olarak tanımlanabilir (EBSO, 2015: 19). Günümüzde, elle yapılan işlemlerin birçoğunun büyük veriyle ikame edildiği takdirde var olan birçok iş gereksizleşebilir bunun yanı sıra şu anda var olmayan farklı iş ya da firsat kategorileri ortaya çıkabilir (Schwab, 2016:156-157).

Artırılmış Gerçeklik (AR), grafiksel bir ortamda ses, grafik, video ya da GPS verileri sayesinde bilgisayarlar vasıtasıyla üretilen insanların duyuları üzerinde etkiye sahip olabilen dijital ortamdaki canlandırmalardır. AR sonucunda, fiziki ve gerçek alanda birleşme meydana gelmekte ve bu sayede kullanıcıya yeni bir algılama sahası oluşturulmaktadır. Bu sayede, görüntü ve alg1 seviyesinde zenginleştirme programı reel olarak uygulanarak, bu ortam etrafındaki ögeler ile etkileşime geçirilebilmektedir. Arttırılmış gerçeklikte, var olan ortamla ilgili sanal bilginin yansimas1 reel dünyayla uyum halindedir (https://www.endustri40.com/artirilmisgerceklik-augmented-reality).

- Bulut Depolama Sistemi sayesinde, örgütler, bulut bilişim sistemine uyumlu yazılımları ile kurumsal işlemlerini gerçekleştirebilmektedir. Yeni ürünle ilgili bilgilerin sisteme eklenmesi ile bulut teknolojisinin performansının yükseltilmesi ve etki tepki zamanının kısalması da gerçekleşebilir. Bulut bilişim ile daha fazla bilgiye erişilebilecek ve üretim hatlarında bilgiye dayalı hizmetlerde verimlilikte artış mümkün olabilecektir (TÜSİAD, 2016: 29).

- Yapay Zeka, insansı olan, algılama, öğrenme, düşünme, çoklu kavramları birleştirme, fikir yürütme, çıkarım yapma, soruna çözüm üretme, iletişim kurma, karar verme gibi bilişsel düzeyi yüksek olan fonksiyonları yapması ya da buna uygun davranışta bulunması beklenen programlardır. Yapay zeka, bilgiyi depo ederek, zaman içinde deneme yanılma yöntemiyle kendini geliştirebilme yeteneğine sahip olup, program tabanlı olarak sistem depo ettiği bilgileri yorumlayabilmekte ve çok süratli tepkiler verebilmektedir. Yapay zeka sahip olduğu özellikler nedeniyle robotik alanlarda yaygın olarak kullanılmaktadır (Bulut \& Akçacı, 2017: 57).

Nesnelerin internet ağına bağlanabilmesi sayesinde, nesneler arasında oluşan iletişim ağ 1 olarak ifade edilen "nesnelerin interneti" ve bu nesnelerden sensörler vasıtasıyla sağlanan veriler "büyük veri" ile bu veriyi hiç zaman yitirmeden işleyen ve bunu anlamlandıran algoritmalara da "öğrenen makineler" gibi yapay zeka 
Endüstri 4.0 Devriminde Robotik Kaynaklar Yönetimi Bağlamında İnsan Kaynakları Yönetiminde Yeni Açılımların Kaçınılmazlı̆̆

denmektedir. Reel dünyadan elde edilen veriler derhal akıllı fabrikalarda değerlendirilecek ve böylelikle üretim optimal düzeyde gerçekleştirilecektir (Bilgin \& Işı1k, 2018: 863). Bu bağlamda, Endüstri 4.0'ın getirdiği yeniliklere ilave olarak, ilerleyen zaman içinde şu an öngörülemeyen birtakım yenilikleri de getireceği söylenebilir.

\subsection{Endüstri 4.0'ın Paradokslarl}

Endüstri 4.0 ile, robotik teknoloji ve otomasyona olan alakanın çoğalması, bu teknolojik gelişmelerin hayatımızı değiştirme potansiyeli ve robotik kullanımda dahil olmak üzere işlerde otomasyonun etkisinin artması nedeniyle endişe yaratması, toplumun bütün kesimleri için hayati derecede önem taşımaktadır. Öte yandan, otomasyon ve robotların getirdiği üretkenlik, rekabetçilik ve yeni işler yaratılmasına yaptıkları olumlu etkilerden de siklıkla bahsedilmekte (Firat \& Firat, 2017: 12), bu iki zıt durum paradoksal bir özellik göstermektedir.

18. yüzyılda yaşanan Sanayi Devrimi'nin ilk dönemlerinde yeni icatlar sayesinde, fabrikaların üretimi önemli ölçüde artmıştı. Bu gelişme, işgörenlerin işini kaybetmelerine yol açabilirdi. Bu nedenle, bazı işgörenler "sabo" isimli sert ahşaptan yapılmış olan giydikleri terlik/takunyalarını işleyen makinelerin dişlilerine atarak, makinenin hassas parçalarını bozuyor ve işleyen üretim hattını durduruyorlardı. Yapılan bu saldırılar daha sonra "sabotaj" ismiyle bilinmeye başladı (http://www.liberalizm.tv/ilerlemeyi-nasil-sabote-edersiniz/). İnsan, mevcut durumunu tehdit ettiği durumlarda değişime direnç göstermiştir. Sabotaj, kelimesi de değişime dirençten gelmektedir.

Tarihi süreçte yaşanan bütün endüstri devrimleri incelendiğinde, kendi içinde bazı olumlu/olumsuz paradoksları taşıdığı ifade edilebilir. Birinci endüstri devrimi sonucu yaşanan gelişmelerle daha fazla üretim yapılıp, insanların yaşam standartları artarken öte yandan fakir ve güç şartlar altında emek veren bir işçi sınıfının ortaya çıktığ1 görülmektedir. Günümüzde Endüstri 4.0 devriminin getirdiklerini gözlemlediğimizde, insan gücüne duyulan gereksinim azalmakta, bununla birlikte nitelikli insana duyulan gereksinim artmakta; insanın sayısal çokluğu değil, sahip olduğu yetenekleri önem kazanmaktadır (Özdoğan, 2017: 13-15).

Endüstri 4.0 ile beklenen en önemli iki korkudan bir "güvenlik" kaynaklı iken, diğeri de "robotik sistemlerin çok yaygın kullanımı sonucu istihdam kaybı yaşanması" tehlikesidir. Bu tür endişeler, önceki yaşanan sanayi devrimlerinde de benzer şekilde yaşanmıştır. Ancak, fiili durum aynı olmamakla birlikte, Endüstri 3.0 'ın getirdiği ekonomik büyüme ve refah artışı, yeni ve inovatif iş alanlarının ortaya çıkmasına, farklı mesleklerin doğmasına (örneğin, otomasyon robot ve makinelerin tamir/bakımı gibi) yeni iş firsatlarının doğmasına yol açmıştır. Dünyada gerçekleşen her yeni gelişmenin, yeni birtakım firsatları doğurduğu ve çağın gerektirdiği nitelikli işgücüne olan ihtiyacın artacağı öngörülmektedir (Acaralp, 2017: 8).

İstihdam konusunda yaşanan en önemli endişelerden birisi de, gelecek zaman diliminde robotların mevcut işgörenlerin yerini alabileceği ve zaten yaşanmakta olan 
işsizliğin daha da artabileceği kaygısıdır. Geçmişte yaşanan sanayi devrimlerinin başında da bu türden endişeler yaşanmasına karşın, her dönemde yeni teknolojik gelişmeler, beraberinde yeni iş alanlarının ve becerilerin gelişmesine de katkı sağladığından, işsizliğin uzun dönemde artması beklenmemektedir. Bununla birlikte, çok önemli iki sonucun ortaya çıkması da kaçınılmaz görünmektedir. Birincisi, mevcut çalışma sürelerinin giderek daha da kısalması ve ikinci olarak, daha kalifiye bir işe ve kariyere sahibi olabilmek için daha yüksek donanımlar ve daha iyi bir eğitimin gerekliliğidir (Taş, 2018: 1827).

Bütün bunların aksine, Endüstri 4.0'ın istihdam kaybına yol açacağ1 yönündeki endişelerin yersiz olduğu düşüncesine sahip olan görüşlerde bulunmaktadır. $\mathrm{Bu}$ endişelerin gerçekçi olmadığını test etmek için 3.0 Endüstri Devrimi dönemine göz atmak yeterli olacaktır. Bu dönemde özellikle otomotiv sektöründe otomasyon artarken, beklendiği gibi işsizlik artmamıştır. Tam aksine olarak, 3.0 Endüstri Devrimi'yle ekonomik büyümeyle birlikte, yeni ve inovatif iş sahalarının doğmasına, farklı ve yeni işkollarının ve mesleklerin iş hayatında yerini almasına, iş olanaklarının artmasına yol açan gelişmeler yaşanmıştır. Endüstri 4.0 ile de yeni iş olanaklarının ortaya çıkacağı kesindir. Endüstri 4.0 ile birlikte yatırımların kısa dönemde $\% 6$ düzeyinde istihdam artışına yol açacağı, uzun dönemde ise başta bilgi teknolojileri ve mekatronik sahalarında olmak üzere donanımlı iş gücünün ciddi düzeyde talep edileceği öngörülmektedir (Özsoylu, 2017: 57).

Ayrıca, yeni teknolojik gelişmelerin sebep olacağı birtakım olumsuzluklar olabileceği gibi birtakım faydaları da olacaktır. Bunlar arasında, insan sağlığına büyük zarar veren oldukça tehlikeli iş kollarında (kimya, sentetik boya, maden vs.) işgören yerine robotların çalıştırılması sayılabilir. Bu suretle boşa çıkan işgörenlerin de eğitilerek, farklı sahalara kaydırılması ile istihdama yeniden kazandırılabilir, mevcut durumda çalışmak istemeyenlere ise tazminat ödenerek ya da emekli edilerek çözümler üretilebileceği tahmin edilmektedir (Bozlar, 2018: 65).

Üretilen ürünler robotlar tarafından tüketilmeyeceğine göre ve bunları tüketmek isteyenin, bir iş ve gelirinin, kısaca parasının olması gerektiğine göre yakın gelecekte, yeni bir realizasyon krizi veya aşırı üretim kaynaklı sorunlar karşımıza çıacaktır. $\mathrm{Bu}$ yüzden, Endüstri 4.0 için sunulan bu yapıyı düşünmek ve olgunlaştırmak için biraz daha zamana gereksinim vardır (Aksoy, 2017: 39). Bu zamanı etkin değerlendirerek, paradokslarda getiri götürü hesabını iyi yapanların, küresel rekabette avantaj sağlayacağı söylenebilir.

\subsection{Endüstri 4.0'in Yeni İş Kolları}

Endüstri 4.0 beraberinde daha önceden olmayan iş sahaları ve iş kollarını getirmektedir. Bunlar (Şener \& Elevli, 2017: 29-30):

1. Endüstriyel Yazılım Programcıları,

2. Bilişim Sistemleri ve Nesnelerin İnterneti Çözüm Üreticisi,

3. Endüstriyel Veri Analiz Uzman1,

4. Robot Koordinatörü, Programc1s1, Tamircisi,

5. Üretim Teknolojileri Uzman1, 
Endüstri 4.0 Devriminde Robotik Kaynaklar Yönetimi Bağlamında İnsan Kaynakları Yönetiminde Yeni Açılımların Kaçınılmazlı̆̆

6. Akı1lı Şehirler Planlayıcılar,

7. Ürün Tasarımcısı ve Üreticiler.

Dünya Ekonomik Forumu tarafından hazırlanan "İşlerin Geleceği (Future of Jobs Report)" adlı raporda (WEF, 2016; Firat \& Firat, 2017: 15-16) yer alan baz1 saptamaları özetlemek konuya 1şık tutacaktır:

- Popülerliği fazla olan bir öngörüye göre; bugün ilkokul eğitimine başlayan çocukların \% 65 ' $i$, günümüzde henüz ihdas edilmemiş yeni bir iş türünde çalışmaya başlayacak.

- Böylesine hızla değişen bir istihdam ortamında, devlet yönetimindekiler, örgütler ve bireyler için, gelecekteki yeni çıkacak işlere yönelik eğitim, bilgi ve beceri kazanımları hayati derecede önemli rol oynayacaktır.

- Endüstri 4.0 devriminde istihdamın, yetenek yönetimi ve beceri kazandırma ile dönüşüm etkisini yeni gerekliliklere göre yönetmek için paydaşlar teşvik edilecektir.

Dijital entegrasyonlar ve büyük veri ile yeni firsatlar ve oluşumlar sayesinde, hayal edilemeyecek ölçüde yeni işler ortaya çıkmaktadır (Soylu, 2018: 50; Taş, 2018: 1830). Bu bağlamda, öngörülen ve öne çıkan işlerin yanı sıra şu an için öngörülemeyen ve 4.0 süreci işlerken ortaya çıacak ihtiyaçtan dolayı, birçok iş kolunun ve mesleğin de zaman içinde hayat bulacağı söylenebilir.

\section{Robotik Kaynaklar Yönetimi}

Yakın gelecekte Robotik kaynaklardan yararlanmanın hayatımızın önemli bir bölümünde etkin rol oynayacağı düşünüldüğünde, artık yeni bir kavram geliştirmeye "Robotik Kaynaklar Yönetimi” kavramına ihtiyaç duyulmaktadır. Yakın gelecekte "Robotik Kaynaklar Yönetimi”, günümüzdeki İKY'nin tamamlayıcısı olacaktır. Aşağıdaki tespitler bunu destekler niteliktedir:

- Massachusetts Teknoloji Enstitüsünden, Bilgisayar Bilimleri Yöneticisi Edward Fredkin, BBC kanalına röportajında şu çarpıcı yorumu yapmıştır: "Tarihte üç büyük olay vardır. Bunlardan ilki kainatın oluşumu, ikincisi yaşamın başlangıcı, üçüncüsü de yapay zekanın ortaya çıkışıdır.” (Acar, 2007: 1).

- Yapay zeka ile erişilmek istenen, rasyonel kararlar alabilen, insan davranışına uygun paralel bir sistem geliştirmektir. Yapay zeka ile rasyonel karar alma ve bilginin tekrardan üretilmesi sonucu, belli kurallara dayanan, kontrollü ve tarafsız sürecin meydana gelmesi imkan dahilindedir (Claudé \& Combe, 2018: 18; Önder \& Sayg111, 2018: 646).

- Yakın gelecekte, yapay zekanın günümüzde insanlar tarafindan yapılan birçok işlevi üstleneceği öngörülmektedir. 2025'de kurumsal denetimlerin \%30 oranında yapay zeka tarafindan yapılması tahmin edilmektedir. Yapay zekanın kullanımının yaygınlaşması, örgütlerde maliyet tasarrufu, prodüktivite artışı ve inovasyon firsatları yaratması beklenmektedir (Soylu, 2018: 53).

- Yapay zekanın gelecekte insan yaşamında gelebileceği nokta, akı1lı fabrikadan tüketiciye "insansız" olarak üretim ve dağıtımın gerçekleşmesi şeklinde örneklendirilmektedir. Geliştirilen yapay zeka sayesinde, nesnelerin interneti ile 
öğrenen makinelerin etkileşiminin sağlanması sonucu, akıllı robotlar tarafından üretilen ürünler, yine nesnelerin internet iletişimi ile hiçbir insanın emek gücü harcanmadan doğrudan adresimize ulaşabilecek ve akılll evlerimiz sayesinde verdiğimiz siparişlerimiz belki de biz evde yokken dahi teslim alınabilecektir (Bulut \& Akçac1, 2017: 51).

Uluslararası Robotik Federasyonu tarafindan ortaya konulan, "Robotların Verimlilik, İstihdam ve İş Üzerindeki Etkileri” başl1klı rapordaki temel bulgular (IFR, 2017; Furat \& Firat, 2017: 12-13):

1. Robotlar, verimlilik ve rekabet gücünü artırıcı katkı sağlar.

2. Otomasyon, iş yaratılması ve ücretlerde artış sağlar.

3. Robotlar, insan emeğini tamamlar ve işgücü kapasitesinde artış sağlar.

4. Hükümetler ve örgütler, robotların istihdam, iş kalitesi ve elde edilen ücretler üzerinde pozitif etkisini sürdürmek için şu an ve gelecekte çalışanlara yönelik doğru beceriler kazanmalarına odaklanmalıdır.

Ayrıca aynı Raporda özetle:

1. İstihdam ve mevcut mesleklerin geleceği konusundaki endişeler, tartışmalara ve siyasi kaymalara yol açar.

2. Çoğunlukla söylendiği şekliyle "otomasyonun iş katili" olarak sunulması değil, otomasyonun işlevinin tartışılması öne çıkıyor. Ancak birbiri ile zıt düşen iki farklı bakış açısının test edildiği istatistiki bulgular henüz mevcut değildir, farklı görüşlere dayalı kalitatif araştırma sonuçları bulunmaktadır.

3. Araştırmalar, robotların işgörenin yerini almaktan ziyade işçiliği tamamladığını, daha da güçlendirdiğini tespit etmektedir. Ayrıca, iş kalitesini ve yaratılan yeni işlerin ücretleri yükselttiğini göstermektedir.

4. Otomasyon ve Robotlar, yakın gelecekte çalışma şeklimizi daha farklı hale getirecektir. Artan verimliliğin yanı sıra ulusal/uluslararası rekabet edebilirlik düzeyi ile artan kalite çok yüksek potansiyel oluşturacaktır.

5. Hükümetler ve örgütler, işgörenlere, iyileştirmelerin kazanımlarını sağlayacak elverişli bir ortam oluşturmak için çalışmalıdır.

Ulusal yapay zeka stratejisinde dünyada ilk 10 arasında yer almayı hedefleyen Avrupa Birliği üyesi Malta, yapay zeka robotlarına vatandaşlık verilmesi için pilot bir projeye başladı. Suudi Arabistan da 2017 yılında, merkezi Hong Kong'da bulunan Hanson Robotics şirketinin ürettiği Sophia adlı robota vatandaşlık verdiğini duyurmuştu (Sungunay, 2018: 149). Bu bağlamda, yakın gelecekte robotların da tıpk1 insanlar gibi ülke vatandaşlı̆̆ 1 statüsünde değer bulacağı söylenebilir.

\section{Robotik Kaynaklar Yönetimi Bağlamında İnsan Kaynakları Yönetimi}

Endüstri 4.0 devrimi insan kaynaklarının endişe ettiği, korkulu bir rüya $\mathrm{m} 1$ olacak? Ya da önceki yaşanan endüstri devrimlerinin sonuçlarına benzer şekilde insan kaynaklarını yeni farklı bir seviyeye mi yükseltecek? Endüstri 4.0 devriminin insan kaynaklarını nasıl etkileyeceği hakkında farklı düşünceler ileri sürülmektedir. Bir taraf, Endüstri 4.0 ile birlikte insan kaynağ 1 istihdamının farklılaşarak büyüyeceği düşüncesini ileri sürerken; diğer bir taraf Endüstri 4.0'nn getirdikleri ile 
Endüstri 4.0 Devriminde Robotik Kaynaklar Yönetimi Bağlamında İnsan Kaynakları Yönetiminde Yeni Açılımların Kaçınılmazlı̆̆

üretim ve öteki alanlardaki muhtemel etkilerinden hareketle, işsizliğin giderek daha da artacağını ve sonuçta dramatik bir tablo yaşanacağını iddia etmektedir (Asiltürk, 2018: 536). Bunlara benzer görüşlere önceki sanayi devrimlerinde de rastlanılmıştır. Örneğin konfeksiyon üretimine geçiş, geleneksel terziliğin iş alanını geriletmiştir. İş yapış biçimlerindeki değişikliklerin bazı iş alanlarını ön plana çıkarırken bazılarını geriletmesi, gelecekte bazı rutin işlerde robotik kaynaklardan yararlanmanın yaygınlaşacağını göstermektedir. $\mathrm{Bu}$ durum bazı insanların işini kaybetmesi sonucunu doğururken, insan kaynakları için yeni iş alanları ve yeni yetkinlikler kazanması firsatını da ortaya çıkaracaktır.

Toplam kalitenin odağında yer alan "kurumları vasıflı insanlarla yönetmek" düsturu Endüstri 4.0 ile evrilecek ve modern hali Kalite 4.0 olacak ve "Kurumları donanımlı, dijital teknolojilere hakim insan kaynağ ile süreçleri yönetmek" şeklinde geliştirilerek küresel rekabet avantajına odaklanılacaktır (Gümüşoğlu, 2019: 551). Küresel rekabet avantajı kazanmak artık alışılagelmiş kalıpların dışına çıkılması, robotik kaynaklardan yararlanma ve insan kaynaklarına yeni yetkinliklerin kazanımı halinde mümkün olabilecektir.

Endüstri 4.0 ile niteliksiz insan kaynağı önemini kaybedecek, nitelikli insan kaynağ1, özellikle de bilgi ve iletişim teknolojisi ile ilintili meslekler önem kazanacaktır. Endüstri 4.0 ile veri analistliği, veri madenciliği, vs. türünde meslekler ön plana gelirken, enerji ve medya sektörlerinin önemi artacaktır. Endüstri 4.0 ile birlikte eski işgörenlerin hakları ve eğitimleri ile yeni işe başlayanların donanımlı yetiştirilmesine yönelik eğitim programlarının, yeni gelişmeler ışığında, yeniden planlaması gerekmektedir (WEF, 2016). Bu sayede insan kaynakları yönetiminin, robotik kaynaklar yönetimi ile işbirliğine yönelik kazanımları içselleştirecek gelişmeler göstermesi bir seçenek olmaktan ziyade zorunluluk olmaktadır.

Robotlar, sermayedarlar için ideal işçilerdir; acıkmazlar, izin istemezler, şikayet etmezler, uyumazlar, sağlı ihtiyaçları yoktur, zam istemezler vs. (Aksoy, 2017: 38), özetle insana göre, tercih edilecek birçok özelliklere sahiptirler. "Karanlık fabrikalar" olarak isimlendirilen insansız akıllı fabrikalarda, işgörene maaş ödeme, verim düşüklüğü, işe devamsızlık ve ayrıca işgörenin ulaşımı için servis giderleri, sağlık giderleri, kıdem tazminatları, toplu sözleşmeler vb. gibi işveren üzerinde baskı yaratan hususlar gündem dişı kalmaktadır (Fırat \& Fırat, 2017: 16). Bütün bu gerçekler, rutin işlerde robotik kaynaklardan yararlanmanın ve insan kaynağının ikamesi olmasının avantajlarını ortaya koymaktadır.

GeminoidDK isimli robotun uzaktan, bir insan mı, bir robot mu olduğunu fark etmek çok da mümkün olmamaktadır. Google bünyesinde bulunan yapay zeka şirketi Deep Mind tarafindan yapılan yeni bir çalışmada, yapay zekalara hayal gücü eklendiği, bu yeni kazandırılan özellikle yapay zeka sistemlerinin, yapacakları hareketler üzerine düşünebilmeleri ve bu sayede muhakeme yeteneği edinmeleri anlamına geldiği belirtilmektedir. Bu gelişmelerle, robotik kaynakların yapay zeka uygulamalarının, yeni kazanımlar sayesinde insan beynine benzer halde öğrenme özellikleri (Kayıkçı \& Bozkurt, 2018: 59) mümkün hale gelmektedir. Bu ise çeşitli 
sektörlerde farklı biçimlerde robotik kaynaklardan yararlanmanın yolunu açmaktadır.

Türk bankacılık sektöründe bir ilk olarak Albaraka Türk Katılım Bankası robotik süreç otomasyon uygulamasını başlattı ve ilk robot işe başladı. Aynen bir insan gibi çalışmakta, ortalama bir çalışana göre 3 kat daha hızlı ve 7 gün 24 saat \% 100 verimlilikle çalışarak hatasız olarak işlemleri gerçekleștirmektedir. (28.08.2018 http://ekonomi.haber7.com/ekonomi/haber/2699742-turk-bankada-ilk-robot-isebasladi). Bu gelişme, diğer bankalarda da benzer uygulamaların yaygınlaşacağının bir işareti olup, çeşitli bankalarda da benzer uygulama haberleri çıkmaktadır.

Ülkemizde son yıllarda robotik kaynakların bankacılık sektöründe kullanılması yönünde ciddi çalışmalar yapılmaktadır. Birçok banka bu alana yaptığ 1 önemli yatırımlar nedeniyle, şube kapatma ve işgücü çıkarma yoluna gitmekte, maliyet unsurunu bütün süreçlerde öncelemektedir. Örneğin, ING Bank'ın Operasyon Genel Müdür Yardımcısı Yücel Ölçer "Bankanın robot teknolojileri bölümünde 10 kişi ve 19 robotluk bir ekipleri olduğunu ve 2019 y1lında çalışanlarımızın yaklaşık 55.000 saatlik vakit ayırdıkları işlerin robotize edilmesi sağlandı" şeklinde durumun önemini belirten açıklamada bulunmuştur (www.bloomberght.com/bankada-19-robotumuz-bu-yil-55-bin-saatlik-is-yapti$\underline{2239563) \text {. }}$.

Oxford Üniversitesi'nde 2013'de yapılan bir araştırmaya göre; halihazırdaki istihdamın \%50'sinin gelecek 20 yıl sonunda, ak1ll robotlar ve yazılımlar; yani yapay zeka tarafından gerçekleştirileceği öngörülmektedir (http://noroblog.net/ 2017/04/18/noroblog-podcast-3-bolum-yapay-zeka-bizi-gereksizlestirecek-mi/).

Ayrıca, 2050 yılına kadar, İKY fonksiyonlarından olan işe alma, terfi ettirme, işten çıkartma gibi işlevlerinde robotik kaynaklara devrolacağı, görev tanımlarından, performansın ödüllendirmesine kadar çok sayıda görevin robotik kaynakların yönetiminde olacağı yönünde öngörüler mevcuttur (Kayıkçı \& Bozkurt, 2018: 60). Tüm bu öngörüler 1şığında, gelecek için insan kaynakları yönetimi ile robotik kaynaklar yönetiminin işbirliğine yönelik çalışmaların yoğunlaştırılması gerekmektedir.

Endüstri 4.0 bütün makinelerin işçi olmadan kendi denetimini ve otomasyonunu gerçekleştiren akıllı fabrikalar öngörmektedir. Bu yeni yapısal değişiklik, insan kaynağını eksiltme üstüne kurulu olduğundan, İKY'nin temel fonksiyonlarından olan İnsan Kaynağı Planlama en çok etkilenecek kısımdır (Yılmaz \& Erkollar, 2018: 7). Bu nedenle, bilgi ve iletişim teknolojilerine hakim, yüksek eğitimli, açık fikirli, şeffaf, donanımlı insan kaynăğ, örgüt kültürünü de etkileyecek ve değiştirecektir (Gümüşoğlu, 2019: 555-556). Bu bağlamda yeni örgüt kültürünün, robotik kaynaklardaki gelişmeyle birlikte, İnsan Kaynakları Yönetiminin, "Robotik Kaynaklar Yönetimi” ile beraber ele alınması ve optimum bileşiminin sağlanması üzerine işbirliğine odaklanması gerekmektedir. 
Endüstri 4.0 Devriminde Robotik Kaynaklar Yönetimi Bağlamında İnsan Kaynakları Yönetiminde Yeni Açılımların Kaçınılmazlı̆̆

\section{Sonuçlar}

İnsanlık tarihinin bugüne gelmesinde birçok önemli kilometre taşı olmuştur. Gelişim zincirinin son halkası olan Endüstri 4.0 devriminin, tüm dünyanın odağında olduğu ve kafa yorduğu bir gerçekliktir. Robotik kaynakların hızla hayatımızın bir parçası haline geldiği günümüzde, yeni bir kavrama "Robotik Kaynaklar Yönetimi" kavramına gereksinim duyulmaktadır. "Robotik Kaynaklar Yönetimi"nin İnsan Kaynakları Yönetimi'nin mütemmim cüzü (ayrılmaz parçası, tamamlayıcısı) olarak değerlendirilmesi gerekmektedir. $\mathrm{Bu}$ ise her iki kaynağın işbirliğini zorunlu k1lmaktadir.

Hong Kong'da risk sermayesi yatırımı yapan bir şirketin, yönetim kuruluna bir yapay zeka alarak bu alanda ilk öncü adımı atması (https://www.hkdestek.com/terminoloji/yonetim-kurulunda-bir-robot/), gelecek için örgütlerin yönetim kurullarının yol haritası hakkında da fikir vermektedir. Gelecekte, İnsan Kaynakları Yönetiminin, yetki devri/yetki kullanımında, optimum faydayı sağlayacak şekilde, "Robotik Kaynaklar Yönetimi" ile işbirliği içinde olması kaçınılmaz olacaktır. Gelecekte İKY'nin odaklanacağ temel hususlardan birisi de ne ölçüde çağa uygun nitelikli insan kaynağı, ne ölçüde robotik kaynak kullanımının en optimum bileşimi sağlayacağını aramak olacaktır.

$\mathrm{Bu}$ bağlamda, Google üretimi Alpha Zero adlı yapay zekanın, sadece dört saatlik zaman zarfinda kendi kendine satranç oynamayı öğrenmesi ve Stockfish isimli efsanevi bilgisayar satranç şampiyonu programını ezici sonuçlarla yenmesi (http://www.satrancokulu.com/yazilar/makaleler/caissa-yasiyor-mu-3-alpha-zeromucizesi/) ilginç bir örnektir. Bunu bir insanın yapabilmesi mümkün mü? Yapay zeka, başka bir yapay zekayı tasarlayabilir mi? Yapay zeka, karar mekanizmalarında (Hong Kong örneği düşünüldüğünde) ne kadar etkin pozisyona gelebilir? Yapay zeka insanın performansını denetleyebilir mi? Kendimizi yapay zekaya mı beğendirmeye çalışacağız? İşe alınmamıza, işten çıkartılmamıza yapay zeka mı karar verecek? Yapay zeka, karar mekanizmalarında insanın önüne geçebilir ve son (nihai) karar verici duruma gelebilir mi? Bu soruların cevapları, gelecekteki dünyayı anlamamızı sağlamak için önemli anekdotlar olarak dikkate alınmalıdır. İnsanlık tarihinin hiçbir döneminde olmadığı kadar, firsat ve tehdit paradoksunu birlikte yaşayacağı bir dönem hızla yaklaşmaktadır.

Günümüzde gelişmelerin hızı göz önüne alındığında, zamanın çok hızlı aktığı bir gerçekliktir. Bu zamanın proaktif bir biçimde değerlendirilmesi, stratejik bir yaklaşımla SWOT analizi çerçevesinde güçlü yanlar, zayıf yanlar, firsatlar ve tehditlerin gerçekçi bir şekilde ortaya konulduğu bir projeksiyon geliştirilmesi gerekmektedir. Ülke olarak Endüstri 4.0 konusunda henüz olayın çok başında olduğumuz gerçeğinden yola çıkarsak önceliğimiz, tüm dünyadaki gelişmeleri yakından takip etmek, bu oyunda baş aktörleri yakından izlemek ve onlardan rol çalmak olmalıdır. Bu sayede robotik kaynakların etkin gelişimi sağlanırken, insan kaynaklarının da bu değişikliklere paralel olarak yeni yetkinlikler kazanma yönünde eğitim ve gelişimi önem kazanmaktadır. 


\section{A. Aslan ŞENDOĞDU}

$\mathrm{Bu}$ bağlamda, ülke olarak daha önce kaçırdığımız Sanayi Devrimlerinde olduğu gibi Endüstri 4.0 Devrimini de 1skalamak istemiyor, küresel pazarda etkin bir rol almak istiyorsak, bu konuda ülkenin genç ve yetenekli beyinlerinin önünü açmak, yurt dışı kazanımlarını sağladıktan sonra da bu kazanımları ülke içinde uygulamak yönünde, milli bilincin oluşturulacağı bir stratejik planımızın olması gerekmektedir. Bu sayede beyin göçünü önleyici milli bilinç oluşturulurken, öte yandan, dünya insanlarını kazanmaya yönelik düşünce de stratejik planın bir parçası olmalıdır. Devletin üst düzey yönetiminde görev alanların, bu gerçeklerin 1şığıında Endüstri 4.0 stratejik planına verecekleri yön ve bu yönde kamu ve özel sektörün bu olguyu içselleştirmesi, gelecekteki konumumuzun belirleyicisi olacaktır. Bu ise bir yandan robotik kaynakların gelişimine yönelik çabayı gerektirirken, diğer yandan insan kaynaklarını yeni gelişmeler ışığında ortaya çıkan/çıkacak olan farklı iş imkânlarına yöneltme ve bu konuda eğitim ve gelişimine yönelik çabay1 gerektirmektedir. Bu çabalar neticesinde ortaya çıkacak yeni konum, gelişmiş ülkelerle birlikte küresel rekabet gücünün içinde olma ya da bu gücün dışında kalma sonucunu doğuracaktır.

\section{Kaynaklar}

Acar, E. (2006), Ölümlülük, Ölümsüzlük ve Yapay Zeka, İstanbul, Alt Kitap.

Acaralp, M. C. (2017), İnsan Kaynakları Yönetiminde Endüstri 4.0\& Dijitalleşme Etkisi - Yetenek Yönetimi, Akdeniz Karpaz Üniversitesi Sosyal Bilimler Enstitüsü İnsan Kaynakları Yönetimi Final Proje Çalışması, Lefkoşe, Kıbrıs.

Aksoy, S. (2017), Değişen Teknolojiler ve Endüstri 4.0: Endüstri 4.0'1 Anlamaya Dair Bir Giriş, Katkı Teknoloji Dergisi, 4, 34-44.

Alçın, S. (2016), Endüstri 4.0 ve İnsan Kaynakları, Popüler Yönetim Dergisi, 63, 4647.

Asiltürk, A. (2018), İnsan Kaynakları Yönetiminin Geleceği: İk4.0, Journal Of Awareness, 3, 527-544.

Aytaç, Y. (2018), Endüstri 4.0 ve Akıllı Fabrikalar”, Sakarya Üniversitesi Fen Bilimleri Enstitüsü Dergisi, 22 (2), 546-556.

Banger, G. (2017), Endüstri 4.0 Ekstra, Ankara, Dorlion Yayınları.

Bilgin, O. \& Işı1k, H. B. (2018), Dördüncü Sanayi Devrimi ve Türkiye: Ulusal Yenilik Sistemi Çerçevesinde Bir İnceleme, Uluslararası Sosyal Araştırmalar Dergisi, 11 (60), 860-867.

Bozlar, T. (2018), 4. Sanayi Devriminin İşü̈cü Piyasasına Olası Etkileri, İ̧KUR İstihdamda 3í Dergisi, 27, 62-67.

Bulut, E. \& Akçacı, T. (2017), Endüstri 4.0 ve İnovasyon Göstergeleri Kapsamında Türkiye Analizi, ASSAM Uluslararası Hakemli Dergi, 7, 50-72.

Claudé, M. \& Combe, D. (2018), The Roles of Artificial Intelligence and Humans in Decision Making: Towards Augmented Humans? A Focus on KnowledgeIntensive Firms, Department of Business Administration, Umea University Master Thesis. 
Endüstri 4.0 Devriminde Robotik Kaynaklar Yönetimi Bă̆lamında İnsan Kaynakları Yönetiminde Yeni Açılımların Kaçınılmazlı̆̆ı

Davutoğlu, N. A., Akgül, B. \& Yıldız, E. (2017), İşletme Yönetiminde Sanayi 4.0 Kavramı İle Farkındalık Oluşturarak Etkin Bir Şekilde Değişimi Sağlamak, Akademik Sosyal Araştırmalar Dergisi, 5 (52), 544-567.

EBSO (Ege Bölgesi Sanayi Odası) (2015), Sanayi 4.0 Uyum Sağlayamayan Kaybedecek, Ege Bölgesi Sanayi Odası Dergisi, Ekim 2015. http://www.inovasyon.org/pdf/EBSO.Sanayi-4.0_Raporu.Ekim.2015.pdf, Erişim Tarihi: 18.04.2019.

Fırat, S. Ü. \& Fırat, O. Z. (2017), Sanayi 4.0 Devrimi Üzerine Karşılaştırmalı Bir İnceleme: Kavramlar, Küresel Gelişmeler ve Türkiye, Toprak İşveren Dergisi, $114,10-23$.

Gümüşoğlu, Ş. (2019), Bilimsel Yaklaşımlarla Değişim, Dönüşüm ve Kalite 4.0, Dokuz Eylül Üniversitesi İktisadi ve İdari Bilimler Fakültesi Dergisi, 33 (2), 543-568.

http://www.bloomberght.com/bankada-19-robotumuz-bu-yil-55-bin-saatlik-isyapti-2239563, Erişim Tarihi: 05.12.2019.

http://ekonomi.haber7.com/ekonomi/haber/2699742-turk-bankada-ilk-robot-isebasladi), Erişim Tarihi: 10.05.2019.

https://www.endustri40.com/artirilmis-gerceklik-augmented-reality/, Erişim Tarihi: 07.05.2019.

http://noroblog.net/2017/04/18/noroblog-podcast-3-bolum-yapay-zeka-bizigereksizlestirecek-mi/, Erişim Tarihi: 09.05.2019.

http://www.liberalizm.tv/ilerlemeyi-nasil-sabote-edersiniz/,Erişim Tarihi: 25.04.2019.

http://www.satrancokulu.com/yazilar/makaleler/caissa-yasiyor-mu-3-alpha-zeromucizesi/, Erişim Tarihi: 10.05.2019.

https://siberbulten.com/yapayzeka/japonlar-robota-canli-kas-ekledi/, $\quad$ Erişim Tarihi:23.04.2019.

https://www.hkdestek.com/terminoloji/yonetim-kurulunda-bir-robot/, Erişim Tarihi: 24.04.2019.

https://www.webtekno.com/ingiltere-de-bir-futbol-takimi-ekibin-basina-yapayzekayi-getirdi-h61753.html, Erişim Tarihi:26.04.2019.

IFR (The International Federation of Robotics) (2017), “The Impact of Robots on Productivity, Employment and Jobs", A positioning paper.

Kagermann, H., Lukas, W. \& Wahlster, W. (2011), Industrie 4.0-Mit dem Internet der Dinge auf dem Wegzur 4. Industriellen Revolution, Berlin, VDI Nachrichten.

Kayıkçı, M. Y. \& Bozkurt, A. K. (2018), Dijital Çağda Z ve Alpha Kuşağı, Yapay Zeka Uygulamaları ve Turizme Yansımaları, Sosyal Bilimler Metinleri, 1, 5464.

Köroğlu, O. (2015), Nesnelerin İnterneti, Algılayıcı Ağları ve Medya, Akademik Bilişim Konferansı, Eskişehir. 


\section{A. Aslan $S B E N D O \breve{G} D$}

Lee, J., Bagher1, B. \& Kao, H. A. (2015), A Cyber-Physical Systems Architecture For Industry 4.0 -Based Manufacturing Systems, Manufacturing Letters, 3, 18-23.

Mrugalska, B. \& Wyrwicka, M. K. (2017), Towards Lean Production in Industry 4.0, Procedia Engineering, 182, 466-473.

Önder, M. \& Saygıll, H. (2018), Yapay Zeka ve Kamu Yönetimine Yansımaları, Türk İdare Dergisi, 487, 629-668.

Özdoğan, O. (2017), Endüstri 4.0: Dördüncü Sanayi Devrimi ve Endüstriyel Dönüşümün Anahtarları, İstanbul, Pusula Yayınları.

Özsoylu, A. F. (2017), Endüstri 4.0, Çukurova Üniversitesi İ̈BF Dergisi, 21 (1), 41 64.

Schuster, K., Plumanns, L. Kerstın, G., Vossen, R., Richert, A. \& JESCHKE, S. (2015), Preparing for Industry 4.0 - Testing Collaborative Virtual Learning Environments with Students and Professional Trainers, International Journal of Advanced Corporate Learning, 8 (4), 14-20.

Schwab K. (2016), Dördüncü Sanayi Devrimi, Çev.: Z. Dicleli, İstanbul, Optimist Yayınc1lik.

Soylu, A. (2018), Endüstri 4.0 ve Girişimcilikte Yeni Yaklaşımlar, Pamukkale Üniversitesi Sosyal Bilimler Enstitüsü Dergisi, 32, 43-57.

Sung, T. K. (2017), Industry4.0: A Korea Perspective, Technological Forecasting \& Social Change, 132, 40-45.

Sungunay, S. S. (2018), Robotlara Vatandaşlık, Bütün Dünya Dergisi, 12, 147-150.

Şener S. \& Elevli, B. (2017), Endüstri 4.0'da Yeni İş Kolları ve Yüksek Öğrenim, Mühendis Beyinler Dergisi, 1 (2), 25-37.

Taş, H. Y. (2018), Dördüncü Sanayi Devrimi'nin (Endüstri 4.0) Çalı̧̧ma Hayatına ve İstihdama Muhtemel Etkileri, Uluslararası Toplum Araştırmaları Dergisi, 9 (16), 1817-1836.

Tekin, Z. \& Uslu, F. (2018), İşletmelerde Zaman Yönetimi: Endüstri 4.0 İle Ölü Zamanı Sıfırlamak, VI. Uluslararası Çin'den Adriyatik'e Sosyal Bilimler Kongresi Tam Metin Kitabi, Ankara.

TÜSİAD (Türk Sanayicileri ve İş İnsanları Derneği) (2016), Türkiye'nin Küresel Rekabetçiliği İçin Bir Gereklilik Olarak Sanayi 4.0 Gelişmekte Olan Ekonomi Perspektifi,Yayın no; TÜSİAD-T/2016-03/576. http://www.tusiad.org/indir/2016/sanayi-40.pdf, Erişim Tarihi: 26.04.2019.

WEF (World Economic Forum) (2016), Future of Jobs Report: Employment, Skills and Workforce Strategy for the Fourth Industrial Revolution, Global Challenge Insight Report.

Yilmaz, C. \& Erkollar, A. (2018), Endüstri 4.0'1n İnsan Kaynakları Planlamas1 Üzerine Etkileri, 5th International Management Information Systems Conference, October 24-26, Ankara. 